\title{
A Natureza Secreta do Estranho: uma Interpretação Lacaniana da Angústia em Freud
}

\author{
Secret Nature of "The Uncanny": a Lacanian \\ Interpretation of Anguish in Freud
}

La Naturaleza Secreta de lo Ominoso: una Interpretación Lacaniana de la Angustia en Freud

\section{Rosane Zétola Lustoza}

\section{Universidade Federal do Paraná}

http://dx.doi.org/10.1590/1982-370301192014 
Resumo: A Psicanálise considera a angústia um afeto fundamental, porque ela é uma condição da constituição do sujeito. Esse afeto sinaliza a existência de uma defesa. No texto O estranho (1919), Freud afirma que a angústia é disparada pelo retorno de algo familiar que foi recalcado. Baseado na obra de Lacan e comentadores, este artigo demonstra que o familiar que retorna na angústia é o Outro real que interpela o sujeito como objeto de gozo. A importância da interpelação do Outro será deduzida de uma evidência linguística fundamental, o fato de que o sujeito é inicialmente o destinatário do discurso. Argumenta-se que o conceito de interpelação do Outro é uma ferramenta capaz de sistematizar o legado freudiano, oferecendo um princípio-chave que permite conceber "a natureza secreta do estranho". O trabalho visa contribuir para uma compreensão ampliada da gênese da angústia, já que encontrar o fator determinante desse afeto é uma tarefa teórica de grande importância.

Palavras-chave: Lacan. Angústia. Estranho. Interpelação.

\begin{abstract}
Psychoanalysis considers anguish as a fundamental emotion because it is a condition of the constitution of the subject. This emotion signals the existence of defense. In his text The Uncanny (1919), Freud asserts that anguish is triggered by the reappearance of something familiar that has been repressed. Based on the work by Lacan and other authors, this paper demonstrates that the familiar emotion that reappears in anguish is the real Other who interpellates the subject as an object of his enjoyment. The importance of interpellation of the Other will be deduced from fundamental linguistic evidence and the fact that the subject is initially the recipient of the discourse. It is argued that the concept of interpellation of the Other is a tool that can systematize the Freudian legacy as it offers a key principle, allowing us to conceive the secret nature of the uncanny. The paper aims to contribute to a broader understanding of the genesis of anguish because finding the determining factor of this emotion is a theoretically important task.
\end{abstract}

Keywords: Lacan. Anguish. Uncanny. Interpellation.

Resumen: El psicoanálisis considera la angustia como un afecto fundamental, ya que es una condición de la constitución del sujeto. Este afecto indica la existencia de una defensa. En el texto Lo ominoso (1919), Freud afirma que la angustia es provocada por el retorno de algo familiar que ha sido reprimido. A partir de la obra de Lacan y comentaristas, este artículo demuestra que el familiar que regresa a la angustia es el Otro real que interpela al sujeto como objeto de goce. La importancia de la interpelación del Otro se deducirá de una evidencia lingüística fundamental, el hecho de que el sujeto es inicialmente el destinatario del discurso. Se argumenta que el concepto de interpelación del Otro es una herramienta capaz de sistematizar la herencia freudiana, ya que ofrece un principio clave que permite concebir "la naturaleza secreta de lo ominoso." El trabajo tiene como objetivo contribuir para una comprensión más amplia de la génesis de la angustia, ya que encontrar el factor determinante de esta afección es una tarea teórica de gran importancia.

Palabras clave: Lacan. Angustia. Ominoso. Interpelación.

\section{Introdução}

A Psicanálise considera a angústia um afeto fundamental, por ser uma condição da constituição do sujeito. Desde o momento em que Freud (1926 [1925]/2006) a eleva ao patamar de força motriz do recalcamento, a angústia passa a ocupar uma função protagonista na estruturação psíquica.
Dado o lugar de honra que ela ocupa no seio da Metapsicologia, encontrar a condição determinante da angústia constitui uma tarefa de suma importância. Porém, as oportunidades para a manifestação desse afeto são tão diversas entre si que isolar sua lógica é um verdadeiro desafio teórico.

Conforme a clássica tese de Inibição, sintoma e angústia (Freud, 1926 [1925]/2006), 
o fator determinante para a emergência da angústia seria a perda do objeto, que deixaria o sujeito cativo de um excedente pulsional que não encontra descarga adequada. Lacan (1962-63/2005, p. 64) adverte para não se tomar apressadamente como referência a fórmula da ausência do objeto. Não obviamente porque seja falsa, mas sim imprecisa, já que tal tese não tem êxito em fazer a distinção conceitual entre angústiae desejo. Afinal de contas, a perda do objeto poderia perfeitamente suscitar no sujeito a nostalgia ou o anelo pela satisfação perdida, não necessariamente gerando angústia.

A fim de evitar por enquanto a tese da perda do objeto, mas buscando ainda subsídios para uma investigação, a estratégia deste estudo foi tomar como ponto de partida o texto O estranho (Freud, 1919/2006). Artigo que, conforme Lacan (1962-63/2005), seria "o eixo indispensável para abordar a questão da angústia" (p. 51). Ali a angústia é concebida como o afeto suscitado quando algo familiar se torna estranho. O que leva Freud a interrogar-se acerca da "natureza secreta do estranho" (p. 258): quem é esse Outro que habita o mais íntimo de nós?

A hipótese deste artigo é de que, no estranho, vem à tona um velho conhecido, sob a forma de um Outro primordial que nos interpela como objetos de gozo. A angústia é, em seu sentido mais fundamental, uma reação ao perigo representado pela interpelação. Será aqui demonstrado como o conceito de interpelação do Outro é uma ferramenta capaz de sistematizar o legado freudiano, oferecendo um princípio-chave a partir do qual é possível conceber a natureza secreta do estranho envolvida em suas diferentes manifestações.

O interesse maior dessa empreitada é contribuir para uma compreensão ampliada da gênese da angústia. Evidentemente, tal ampliação esbarra também em limites de validade, como é próprio de qualquer trabalho teórico. Isso quer dizer que não se pretende aqui elaborar uma teoria unificada da angústia, o que ficará mais claro nas considerações ao final do artigo.
Espera-se aqui, não só testar a potência do referencial lacaniano de leitura em extrair da obra de Freud uma verdade renovada, mas também, por uma via de mão dupla, mostrar a importância da leitura de Freud para a iluminação de alguns conceitos lacanianos considerados habitualmente obscuros ou de difícil entendimento, como o de Outro real em sua oposição ao Outro simbólico.

\section{A interpelação do Outro: definição}

O fio condutor que nos ajudará a alinhavar a série de observações sobre o estranho é o comentário de Leader (2013, p. 184) acerca de uma dimensão essencial da linguagem: o fato de o sujeito ser fundamentalmente o destinatário do discurso. Em termos ontogenéticos, a linguagem é uma forma de organização que existe previamente ao sujeito, o que coloca a criança na condição primeira de objeto visado pelos enunciados linguísticos que partem do Outro. A situação inicial de qualquer sujeito é a de ser alvo de uma interpelação transmitida por intermédio da voz do Outro. De acordo com o autor, essa posição primária de passividade diante da voz é problemática por duas razões. Primeiro, o sujeito em questão ainda não consegue ligar o som emitido pelos adultos a um sentido qualquer. A criança encontra-se portanto confrontada à difícil tarefa de escutar a série de falas que se dirigem a ela, sem fazer a menor ideia do que estas significam. O bebê se depara com uma interpelação do Outro que se endereça a ele e cujo sentido é perfeitamente enigmático. Em segundo lugar, o sujeito não tem recursos inicialmente para se defender da voz do Outro. Conforme Leader: Quase todas as outras interações com
o adulto podem ser objeto de alguma
forma de contestação, alguma demons-
tração de sua própria subjetividade. A
criança é capaz de questionar o que o
adulto lhe oferece ou lhe pede. Pode
recusar-se a comer, a beber, a usar o
troninho, e assim por diante. Mas o que
ela não pode rejeitar com a mesma faci-
lidade é que o Outro lhe dirija a pala-
vra. (...) O próprio fato de não haver
defesa contra isso concede-lhe um
potencial persecutório. (2013, p. 184) 
O recurso à infância para pensar o caráter traumático da voz nos fornece um acesso mais límpido e cristalino a algo que pertence, no entanto, à estrutura subjetiva. A voz exibe desde o início características que ela nunca irá perder ao longo do desenvolvimento, que serão apenas mascaradas por outros fatores. Mesmo depois da aprendizagem do código da língua pelo sujeito, o significante carrega como sua sombra a voz como resto ineliminável.

Isso emerge de forma muito evidente nas ocasiões em que o sujeito escuta uma palavra cujo poder de penetração o deixa paralisado:

pode tratar-se de uma palavra que surge do discurso de nosso interlocutor e que está, repentinamente, carregada de um poder espantoso, diante do qual nos encontramos sem resposta, uma vez que ela condensa, durante um tempo, a capacidade de suspender nossa aptidão em recusá-la, em contradizê-la, até mesmo em denegá-la. A função de tal palavra (...) pode encarnar-se, no momento mais inesperado, num significante que então advém como traumático (Didier-Weil, 2002, p. 358).

Nesses casos, o significante passa a ter a peculiaridade de induzir ao mutismo, em vez de provocar a fala: "esse saber não é dado, com efeito, como um saber suposto tendo o poder de causa a fala, mas, muito pelo contrário, como um saber impondo silêncio ao sujeito" (p. 358). É comum então o sujeito ser assombrado repetidas vezes pela insistente recordação daquela voz que enunciou a palavra. Se a posteriori tem lugar um impulso incessante para dar sentido ao que se escutou, tal operação não desgasta inteiramente a potência traumática da palavra, que parece não caber em nenhuma roupagem semântica adequada. A persistência da interpelação testemunha a existência de uma dimensão Real no Outro, materializada aqui pela voz, a qual lateja, insiste, sem poder ser inteiramente integrada ao Outro simbólico do saber suposto.

Deve-se aqui tentar uma leitura ampliada e considerar que a linguagem não é apenas um instrumento de comunicação, mas uma condição que medeia a constituição da realidade para o sujeito. Ora, se os enunciados linguísticos participam da própria construção da realidade, inversamente qualquer elemento da realidade pode passar a ter função de interpelação (pelo menos por hipótese). A interpelação do Outro não precisa partir apenas da palavra falada, da voz. Nesse sentido, a psicose nos fornece lições extraordinárias sobre a possibilidade de quaisquer objetos do mundo - até os inanimados - poderem interpelar o sujeito. Numa psicose desencadeada, há de fato um momento em que tudo faz signo, como no ótimo exemplo de Lacan (1955-56/2002):

Um de nossos psicóticos conta-nos em que mundo estranho ele entrou já há algum tempo. Tudo para ele tornou-se signo. Nãosomenteeleéespiado, observado, vigiado, falam dele, julgam-no, indicam-no, olham-no, dão-lhe uma piscadela de olho, mas tudo isso invade o campo dos objetos reais inanimados, não-humanos. (...) Se ele encontra na rua um carro vermelho - um carro não é um objeto natural -, não é por acaso, dirá ele, que esse passou naquele exato momento (p. 18).

A experiência de ser objeto da interpelação do Outro pode então acontecer em várias modalidades distintas (Leader, 2013) - a voz e o olhar são apenas os casos mais notáveis, aos quais poderíamos perfeitamente acrescentar os gestos (quando alguém, por exemplo, assovia ou aponta para nós), ou até mesmo o movimento de um objeto inanimado... Qualquer elemento é, a princípio, passível de nos convocar. Isso quer dizer que a linguagem nos intima primariamente como objetos do Outro.

Se o que nos é inicialmente concedido é o lugar de objeto, é natural que o sujeito ofereça seu corpo a fim de se reunir ao Outro. Não se trata apenas para o sujeito de ser alvo de uma interpelação que o concerne diretamente, mas da satisfação masoquista que ele aí experimenta, na medida em que deixa seu corpo à disposição do Outro. 
Dá para entender porque o problema crucial do sujeito será o de subtrair-se às garras do Outro todo-poderoso. Quando a criança satura inteiramente a falta do Outro, fica enclausurada em um universo fechado e claustrofóbico de autorreferência, onde tudo se torna relativo a ela. Se, por hipótese, existir alguém que seja o único e exclusivo objeto do interesse do Outro, não haverá espaço algum entre o sujeito e o Outro cuja intersecção seja vazia: a sobreposição entre os conjuntos estará praticamente realizada. O indivíduo teria dificuldade de fazer a operação de se retirar do Outro.

A condição de ser objeto do gozo do Outro éo problema fundamental de qualquer estrutura psicopatológica (Van Haute, 2002), de tal modo que as categorias clínicas poderiam ser entendidas como diferentes formas de defesa contra a objetalização. Uma vez que este artigo se debruça mais detalhadamente sobre o tema da angústia na neurose, não se pretende adentrar mais no campo da psicose. Apenas deve-se observar que o estabelecimento de um ponto de partida comum às estruturas não significa a dissolução das diferenças de tratamento dadas por cada uma delas ao problema da interpelação. A interpelação aparece de uma forma muito sensível e imediata no caso de psicose mencionado anteriormente, e é o fato de surgir a céu aberto que faz com que alguém nos apareça justamente como um louco. Ao passo que, na neurose, a interpelação estaria presente também, mas encoberta sob o véu do recalque: o paciente se dá conta dela graças à interpretação, cuja emergência não se dá sem surpresa.

$\mathrm{Na}$ neurose, o trabalho do recalque tem como consequência a drenagem de uma parte considerável do gozo experimentado na interpelação. Como afirma Leader (2013), a função interpeladora da linguagem

(...) pode ser mediada e recalcada, ao ser entremeada nas estruturas simbólicas mínimas da presença e da ausência, e, num outro nível, lida-se com ela no processo da metáfora paterna. O que faz esta senão reatribuir fundamentalmente uma função de destinatário?
Os interesses da mãe já não são dirigidos apenas à criança, mas registrados como voltados para outra pessoa ou coisa, além dela e da criança. Isso afasta o vetor interpelador. Sem essa operação, permanecemos expostos ao vetor (p. 191).

É o retorno do recalcado que testemunha a persistência dessa interpelação da qual quisemos um dia nos separar.

Tentaremos agora demonstrar como essa tese da interpelação do Outro pode servir para desvendar a natureza secreta do estranho.

\section{O estranhamento como defesa contra a interpelação do Outro}

Freud (1919/2006) se dedica em O estranho a analisar um conjunto de fenômenos tão heteróclitos e selecionados de uma forma tão pouco sistemática que parecem nada ter em comum, a não ser o afeto de angústia que despertam. É o próprio autor que sumariza os fatos a serem examinados: "O animismo, a magia e a bruxaria, a onipotência dos pensamentos, a atitude do homem para com a morte, a repetição involuntária e o complexo de castração compreendem praticamente todos os fatores que transformam algo assustador em algo estranho" (p. 260).

A hipótese desse artigo é que, caso tomemos a interpelação do Outro como bússola conceitual que norteia o nosso estudo, estaremos situados em boa posição para discernir o fio que liga as diversas manifestações do estranho elencadas por Freud.

Se o estranhamento "pode-se atribuir, sem exceção, a algo familiar que foi recalcado" (p. 264), busca-se aqui demonstrar como o familiar nada mais é do que o Outro real da interpelação. Para contemplar esse ponto, dividiremos aqueles fenômenos apresentados por Freud em 3 categorias, que os abarcam de forma mais sintética. São elas: a existência de processos sobrenaturais (correspondendo a animismo, magia, bruxaria, 
onipotência dos pensamentos e atitude do homem para com a morte), a repetição (que será aqui lida de forma ampliada, como compulsão à repetição) e o complexo de castração. Tomou-se a liberdade de acrescentar à lista uma quarta categoria que não aparece na passagem citada, mas que é discutida abundantemente por Freud no texto: o estranhamento diante do duplo.

\section{a) A existência de processos sobrenaturais}

O sentimento de estranheza pode ser suscitado quando o sujeito testemunha a emergência de algo cuja causa não poderia ser encontrada facilmente na realidade natural. A incapacidade de ligar o efeito a alguma causa física levaria à hipótese da existência de uma causalidade extra-física, o que produziria em nós uma impressão assustadora.

Freud (1919/2006) ligará engenhosamente a causa sobrenatural a um momento particular de nossa infância, no qual acreditávamos no poder mágico do pensamento, ou seja, de que o mero fato de alguém pensar ou dizer algo seja capaz de provocar transformações no mundo objetivo, independente de qualquer ação. Tal atitude releva da onipotência de pensamentos, isto é, da crença que os desejos de alguém possam automaticamente transformar-se em realidade, sem levar em conta as leis da natureza.

A crescente racionalização de nosso relacionamento com o mundo objetivo fez com que as antigas crenças animistas fossem recalcadas. A função do princípio de realidade seria precisamente permitir ao sujeito traçar uma linha de fronteira que estabelece quais ocorrências são possíveis e quais são impossíveis. Ora, o efeito de estranheza surgiria justamente quando ocorre um apagamento provisório do teste de realidade: no momento em que o impossível acontece-sob a forma da aparente intervenção de uma causa não-física -, o critério de distinção entre o verdadeiro e o falso, entre a realidade e a ficção, fica completamente abalado. O abalo do teste de realidade equivale ao colapso de nossa capacidade de verificação.
Essa rubrica permite reunir inúmeros dos fenômenos relatados por Freud no texto. Tomemos o temor de que objetos aparentemente inanimados subitamente ganhem vida, ou, inversamente, de que seres aparentemente vivos revelem-se cadáveres (1919/2006, p. 244): o que verdadeiramente está em jogo é que tais eventos colocam à prova nosso critério de verificação da intencionalidade de um ente, que distingue quem as possui dos que são desprovidos dela. $\mathrm{Ou}$ seja, trata-se de eventos que colocam sob suspeita o nosso teste de realidade. Outro exemplo é o do paciente que, depois de desejar a morte de um senhor - percebido como obstáculo ao desejo -, recebe, duas semanas depois, a notícia surpreendente de que o velhinho sofrera um derrame (p. 256). Tal fato é percebido pelo paciente como uma demonstração da eficácia mágica do seu pensamento; o que, de novo, desafia o princípio de realidade. Ou ainda o caso do indivíduo a quem ocorre deparar-se repetidas vezes no dia com a ocorrência do número 62 (p. 255): mesmo não sendo supersticioso, é difícil para ele não atribuir ao evento um significado oculto, uma intenção obscura que estaria na origem das coincidências. De novo, o princípio de realidade é posto em xeque.

O princípio de realidade é o nome freudiano do Outro simbólico, o suporte das regras que tornam o mundo coerente e dotado de sentido. É uma tese lacaniana a de que o nosso sentimento de realidade depende da maneira pela qual um conjunto de regras interpretam os acontecimentos para nós. A realidade tem a estrutura de uma ficção, uma cena contada pela historicização feita pelo Outro:

A dimensão da cena, em sua separação do local em que está o espectador, está aí para ilustrar a nossos olhos a distinção entre o mundo e o lugar onde as coisas, mesmo que sejam as coisas do mundo, vêm a se dizer. Todas as coisas do mundo vêm colocar-se em cena segundo as leis do significante (...). Primeiro tempo, temos o mundo. Segundo tempo, o palco em que fazemos a montagem desse mundo. $\mathrm{O}$ palco é a dimensão da história. A história tem sempre um caráter de encenação (Lacan, 1962-63/2005, p. 42-43). 
Freud (1919/2006) demonstra claramente saber disso quando alude a um fato interessante: em certas narrativas literárias, a irrupção do sobrenatural não provoca no leitor o sentimento de estranheza - como é o caso, para usar um exemplo próximo a nós, do realismo fantástico latino-americano. Isso acontece porque "adaptamos nosso julgamento à realidade imaginária que nos é imposta pelo escritor, e consideramos as almas, os espíritos e os fantasmas como se a existência deles tivesse a mesma validade que a nossa própria existência tem na realidade material" (p. 267). Em outras palavras, o escritor imaginativo estabelece em seu texto uma série de regras que funcionam como teste de realidade, separando o possível do impossível. Se conversar com uma mulasem-cabeça for considerado algo corriqueiro ou possível pelas normas internas à obra, o efeito de estranheza não ocorre.

A pergunta a ser feita é: quando a cena montada pelo Outro é questionada, o que emerge em seu lugar? Discorreu-se mais acima sobre a existência de uma dimensão interpelativa na linguagem: nela se está confrontado à voz do Outro, ao seu olhar, ou a qualquer outra modalidade sensorial, desde que esta materialize uma intenção que visa ao sujeito e da qual é impossível escapar. Ora, não é justamente essa vertente do Outro o que ameaça vir à tona no estranho? Eis aqui uma forma primeira de aparição do Outro, na qual este ainda não foi ainda domesticado, ou enquadrado por uma lei: com esse Outro caprichoso, tudo se torna possível.

Aqui, evidencia-se a equivalência entre a onipotência de pensamento tematizada por Freud e essa intenção que interpela o sujeito, da qual não se tem recursos para fugir, e cujo significado é obscuro. A onipotência de pensamento é, primariamente, a onipotência do Outro primordial, de um Outro de cujas garras o sujeito não pode subtrair-se.

Poder-se-ia retrucar que a onipotência de pensamento mais comumente descrita por Freud é a do sujeito, não a do Outro. Quanto a isso, deve-se compreender que a onipotência infantil nada mais é que a repetição do poder totalitário que a criança um dia atribuiu aos seus pais. Se a forma preferencial de interferência de uma criança nos assuntos do mundo se dá primeiramente por via mágica, é porque ela tenta reproduzir por conta própria uma atitude que originalmente atribuiu aos adultos.

Observe-se que o estranho coloca em ação um desdobramento do lugar do Outro. Há o Outro primeiro da interpelação, ainda não colonizado por uma lei que o faça ingressar numa regularidade. Mas há também o Outro simbólico, drenado de gozo, capaz de representar o espaço vazio de intersecção entre o sujeito e o Outro materno primordial. Em termos simples, temos o esquema lacaniano em que o Nome-do-pai se substitui ao Desejo da Mãe. O Nome-do-pai abre espaço para uma interpretação do mundo que o destitui (em parte) de sua irracionalidade, da hiperpermeabilidade a uma poderosa intenção que atravessa a natureza inteira, que Freud (1919/2006) não por acaso compara ao animismo.

Isso já nos encaminha para um outro tema: se o recalque é correlato da instauração do princípio de realidade, está claro que um abalo que afete a credibilidade do grande Outro incorrerá no retorno do que foi recalcado. Se o Outro simbólico abre o espaço de um certo horizonte de compreensão a partir do qual os fatos da realidade se organizam, o abalo da perspectiva de avaliação do Outro compromete a nossa experiência do sentido das coisas. Essa lacuna deixada pelo Outro é um vazio no qual alguma coisa entra: o retorno da interpelação recalcada, sob a forma da voz, do olhar, etc.

Retornemos a outro exemplo favorito de Freud, o do mau-olhado. Quando o sujeito perde uma coisa que conquistou a duras penas, e pela qual era profundamente invejado, é comum sentir estranhamento, como se um feitiço houvesse funcionado. Tal efeito manifesta uma divisão subjetiva, onde convergem duas correntes contrárias, ambas pertencentes ao sujeito: a primeira, o impulso fascinado de nos abandonarmos ao olhar invejoso de alguém, cuja interpelação 
nos leva a entregar tudo o que nos é precioso; contra este impulso, manifesta-se uma defesa, a qual visa a sustentar a racionalidade da realidade, a submissão do mundo a Leis impessoais, alheias ao querer das vontades particulares. A angústia é aqui um sinal de alarme, uma defesa contra a recrudescência da onipotência materna, do animismo primitivo, do pensamento mágico, em síntese, de um mundo onde tudo é possível, pois não há lei, onde o que impera é o capricho de um deus obscuro.

O importante a frisar não é simplesmente que há um Outro fora de nós que nos subjuga, mas principalmente que nos esforçamos por lutar contra o impulso, dentro de nós, de nos fazermos de objeto para o Outro. Nesse sentido, o sujeito se ampara na Lei simbólica como forma de proteção contra esse poderoso impulso. "(...) a lei deve tanto proteger-nos contra a ameaça de um Outro super-invasivo quanto nos impedir de lutar para entrar em fusão com ele - uma unidade onde toda distinção estaria perdida e o sistema simbólico entraria em colapso" (Van Haute, 2002, p. 223).

A interpelação oriunda do Outro não deve ser pura e simplesmente identificada com uma intenção malévola - embora possa até assumir essa forma. O conceito permite reunir uma ampla gama de fenômenos, desde aqueles que exibem uma coloração mais "positiva" (como a criança que almeja ser tudo para a sua mãe, até mesmo ter relações com ela) até aqueles cuja componente "negativo" é maior (como o sujeito que se faz destruir pelos outros). A questão relevante aqui é a existência de um impulso para se entregar como objeto ao Outro, para saturar o Outro, independente de boas ou más intenções. Se pudermos caracterizar esse impulso com qualidades mínimas, definiríamos como um impulso que não respeita as barreiras do prazer, do bem-estar, da auto-conservação. O nome freudiano desse impulso é pulsão de morte.

b) A repetição

Em Além do princípio do prazer, Freud (1920/2006) aborda a compulsão à repetição como a perpétua recorrência de um mesmo na vida dos pacientes: "a impressão que dão é de serem perseguidas por um destino maligno ou possuídas por algum poder demoníaco" (p. 32). Conhecemos os exemplos: o benfeitor que é sempre abandonado por seus protegidos ingratos; o homem cujas amizades sempre se concluem com uma traição; a mulher que ficou viúva três vezes... Conhecemos também a hipótese: é improvável que o lançamento de um dado dê o mesmo número várias vezes seguidas, a repetição do mesmo não é obra do acaso. Se há repetição, é porque o sujeito extrai disso uma satisfação, ainda que esta nada tenha de prazeroso.

A repetição é frequentemente ligada pelo próprio paciente à intencionalidade de outra pessoa, tomada aqui como um agente claramente identificável que seria culpabilizado pelo sujeito (falas do tipo Todas as mulheres me abandonam...). Esse é um primeiro nível de abordagem do tema da interpelação do Outro, em que esta é interpretada pelo paciente de forma superficial, como vontade que emana de um Outro consciente. Será próprio da operação psicanalítica realizar dois movimentos: o primeiro é ligar o Outro à história do sujeito, transformando-o num lugar que foi ocupado primeiro pelos pais e depois por seus diferentes sub-rogados; o segundo é implicar o sujeito, assinalando a satisfação que ele encontra em se oferecer como objeto ao Outro.

Note-se que, na compulsão à repetição, há também um encontro com a interpelação do Outro. Afinal, se o sujeito se faz abandonar, se faz trair, se faz enxotar pelo Outro, é porque se oferece masoquistamente como o objeto que satisfaz a Ele. O que há de mais espantoso no autômaton é justamente que o mau encontro passou a ser um destino previamente calculado pelo inconsciente.

Porém, há diferenças relevantes entre a compulsão à repetição e os exemplos da seção anterior, nos quais a repetição aparecia ligada a uma causa "sobrenatural": ali, a situação era mais simples, como no exemplo em que alguém encontrava várias vezes por dia com o número 62. Naqueles casos, estava em jogo 
um mau encontro que era obra do acaso. Não à toa, Freud (1919/2006) classifica tais casos como "repetição involuntária" (p. 260): a coincidência repetitiva se deve ao azar, mas o fato acontecido na realidade desencadeia acidentalmente um processo inconsciente recalcado.

Já na compulsão à repetição temos, ao contrário, um mau encontro programado pelo inconsciente, onde o sujeito participou de forma ativa na produção do resultado (ainda que não tenha clareza sobre como isso se deu). Há uma inversão em relação à repetição dita involuntária: enquanto na primeira o sujeito desempenha um papel passivo, na segunda seu papel é ativo. Embora seja abusivo falar aqui de repetição voluntária, temos um processo que envolve mais diretamente uma mesma escolha fatídica que se reproduz.

Outra diferença entre os dois casos é que a repetição "involuntária" é pontual e localizada no tempo, ao passo que, na compulsão à repetição, a programação inconsciente arquiteta um percurso longo antes de chegar ao resultado. O sujeito não se faz abandonar sem antes passar por uma sequência repetitiva, em que, por exemplo, se apaixona, conquista, casa, para só depois separar-se... O trajeto da pulsão de morte é alongado, fica mais rebuscado, mescla-se com Eros, enfim, o circuito pulsional efetua "détours mais complicados antes de atingir seu objetivo de morte" (Freud, 1920/2006, p. 49).

A sequência repetitiva - no exemplo, apaixonar-se, conquistar, casar, ser abandonado - pode ser entendida como uma cadeia significante. Apesar de existirem variações de conteúdo próprias aos episódios repetitivos, há uma mesma estrutura formal que é reprisada. Miller (1997) afirma que a pulsão é uma cadeia significante inconsciente que produz gozo.

Agora pode ficar mais clara a diferença de tratamento dado ao tema da repetição nos dois textos em exame. É que, em Além do princípio do prazer, Freud (1920/2006) passou a considerar a repetição como a própria forma de satisfação da pulsão, elevando-a ao estatuto de conceito metapsicológico fundamental. A repetição não é mais reduzida a um evento fortuito, localizado no tempo, que elicia de forma casual um conteúdo inconsciente; ela se torna a própria condição de satisfação da pulsão.

Voltando ao tema da angústia, é preciso assinalar que nem sempre a compulsão à repetição angustia o sujeito. O fato é que, quando há angústia, o prognóstico do caso é mais favorável. A abertura para uma intervenção se torna possível, justamente porque a angústia sinaliza uma defesa contra o gozo.

É frequente a angústia se manifestar aqui sob a forma de um estranhamento: o sujeito não consegue acreditar que isso aconteceu de novo, como se pairasse uma dúvida acerca da realidade da repetição. Sua incredulidade é o índice da existência da divisão subjetiva: há no sujeito o poderoso impulso de se fazer de objeto para o Outro, mas há também uma defesa contra esse impulso, que faz objeção ao gozo do Outro, ao impossível esforço de fazer Um com o Outro. Por isso, quando o paciente se angustia diante da repetição, as chances para que o tratamento consiga abordá-la são maiores.

c) O complexo de castração

Lacan (1962-63/2005) põe em relevo na famosa ameaça de castração o fato de que, caso a castração fosse consumada, uma parte de nosso corpo seria separada de nós e viraria um objeto de troca, compartilhado, comum: "esses objetos, quando entram livremente no campo em que não têm nada a fazer, o da partilha, quando nele aparecem e se tornam reconhecíveis, têm a particularidade de seu status assinalada a nós pela angústia" (p. 103). Isso ocorre porque o corpo próprio seria anterior à constituição do espaço dos objetos comuns, socializáveis. Quando o mais íntimo do nosso corpo se torna um objeto exteriorizado, o estranho emerge.

No entanto, deve-se ir além dessa observação e buscar as coordenadas que tornam possível a aparição da angústia. Já Freud (1919/2006) buscou admiravelmente estabelecer essas 
coordenadas ao recorrer ao conto Homem da Areia (Hoffman, 2010). Sabe-se que a raiz do sentimento de estranheza no conto está diretamente ligado ao temor que o jovem Nataniel tem de ser mutilado pelo Homem da Areia, personagem cruel que arrancava os olhos das crianças desobedientes. Conforme a análise freudiana, o Homem da Areia não passa de um substituto "do pai temido, de cujas mãos é esperada a castração" (Freud, 1919/2006, p. 249).

Temos então reunidos alguns elementos: os olhos, parte de nosso corpo, são extraídos e passam a figurar na realidade compartilhada, o que é conforme ao ensinamento lacaniano. Mas há que se considerar a advertência freudiana: a perda do órgão seria perpetrada pelo pai temido. Se Freud usou o sintagma "pai temido" foi porque precisou ele também desdobrar conceitualmente o lugar do pai em dois. Com efeito, há o pai do amor, do bem, representado no conto pelo próprio pai de Nataniel, assassinado logo no início pelo perverso Homem da Areia. Já este último representa o pai temido, que não hesitaríamos aqui em vincular ao Outro primeiro da interpelação.

Temos aqui nova oportunidade para esclarecer a temática do desdobramento do Outro em duas dimensões: há o Pai real de cuja interpelação o sujeito não pode fugir, e a qual ele dá um assentimento obscuro. Mas há também o Pai simbólico, que não por acaso seria melhor representado no conto por um pai morto: como se sua ausência fosse condição necessária para que o sujeito possa se organizar, construir um lugar próprio e liberar-se do esforço de fazer Um com o Outro.

O que ocorre aqui é que o Outro primeiro da interpelação aparece sob uma nova máscara, a voz do Supereu. Recordemos aqui que o Outro simbólico da lei impessoal, que estabelece o limiar entre o possível e o impossível, é posto em xeque quando o impossível acontece-definição exata do real lacaniano. Diante da falta do Outro, entra em cena seu suplemento obsceno, sob forma da lei superegoica. O trabalho do Supereu consiste em interpretar a impossibilidade como um castigo, deixando o sujeito em impotência. Afinal de contas, o Supereu é essa instância internalizada que dá ordens ao sujeito e o ameaça com uma punição. $\mathrm{O}$ estranhamento acontece quando o temido destino vociferado pelo Outro se confirma. O sujeito liga a perda à confirmação de um destino, como se as perdas que ele buscou ou sofreu tivessem o significado profundo de um obstáculo intransponível que foi imposto pela voz tirânica de um Outro cruel.

Na famosa cena freudiana da castração, é preciso nos afastarmos um pouco do fascínio que seu conteúdo exerce sobre nós e darmos importância, não tanto ao órgão fálico ausente, mas à voz que comanda sua mutilação, que se torna a voz do Supereu dentro de mim. A angústia moral se manifesta aqui como defesa contra essa voz.

O ponto importante a não perder de vista é que toda lei superegoica é expressão da interpelação do Outro; mas nem toda interpelação do Outro é expressão do Supereu. Conforme Leader (2013), mesmo uma criança muito pequena já esta assujeitada aos enunciados linguísticos do outro, na medida em que é sua destinatária. Ou seja, a interpelação pode ser isolada muito precocemente, num ponto anterior ao da construção do Supereu. Essa é a razão pela qual Lacan (1962-63/2005) observa que o Supereu não é a causa do masoquismo: o masoquismo é, antes de tudo, fundamental, constituindo o masoquismo moral um dos seus derivados.

d) O duplo

O estádio do espelho demarca um tempo de constituição da imagem do corpo como res extensa, ou seja, como algo que ocupa um lugar determinado no espaço e no tempo. A montagem do estádio do espelho coloca em ação dois tipos de identificação: a mais evidente é a imaginária, na qual me identifico com a imagem idealizada que vejo refletida na superfície; a outra é simbólica, na qual me identifico com o ponto de vista a partir do qual um valor será atribuído àquela imagem. O ponto de vista evidentemente não faz parte do conteúdo observado; do 
mesmo modo que um critério de avaliação qualquer não se confunde com os objetos que ele avalia. A perspectiva de avaliação, proveniente do Outro, disponibiliza uma grade interpretativa graças a qual tanto o ego (moi) quanto os objetos da realidade empírica podem ser significados.

Quando observo o mundo pelas lentes do Outro, posso enxergar tudo, exceto o próprio olhar, já que este se encontra inteiramente mergulhado naquilo que vê. Conforme Brousse (2007), quando o olhar está comprometido com a perspectiva do Outro,

a peculiaridade é que eu me suprimo de mim mesmo. Eu te vejo na medida em que não vejo a mim mesmo. Então, o funcionamento do olhar produz essa característica: todas as nossas relações visuais estão condicionadas pelo fato que nós nos fazemos desaparecer a nós mesmos da cena (p. 9-10).

Que fique claro que o eu (moi) está incluído na cena observada; o que está suprimido é de outra ordem: o próprio olhar como real. Há, no entanto, uma experiência especial, na qual se revela aquilo que normalmente está oculto. No estranhamento diante do espelho, o olhar como ponto que está normalmente excluído do campo visual vem à luz.

O que devemos aqui ter claro é que esse "olhar" não se confunde pura e simplesmente com o discurso historicamente determinado que sustenta a realidade para nós. Não se trata aqui da súbita revelação dos compromissos sócio-simbólicos que tornam a percepção do mundo viável para o sujeito. Se Lacan diz que, no estranho, o objeto a entra em cena, devemos ter em mente que o objeto se opõe ao significante. $\mathrm{O}$ "olhar" como objeto não éa trama significante (S1-S2) que ampara a nossa leitura dos fatos da realidade (como o fazem o discurso cristão, comunista, liberal, etc).

$\mathrm{Na}$ experiência do estranhamento, o sujeito não se reconhece mais na imagem refletida, que se torna, por conseguinte, a imagem de um outro. O mecanismo de inversão especular, graças ao qual é possível dizer que o outro sou eu, fica provisoriamente comprometido. Tal fenômeno deriva de um abalo no campo do discurso do Outro que homologava o valor das imagens: abalo simbólico cuja consequência imaginária é o não reconhecimento no espelho.

Apesar de, no estranho, eu não conseguir me reconhecer na gestalt daquele corpo que vejo, por outro lado me deparo com a presença de uma marca indelével, inscrita em uma parte da imagem, que torna impossível me excluir dela: o olhar. Enquanto no estádio do espelho reconheço a imagem como minha, mas não meu próprio olhar; no estranhamento não "vejo" a imagem (pois não a reconheço mais como minha), mas ganho acesso ao olhar. Na situação normal, a imagem especular do corpo é um continente do olhar; na situação de estranheza a imagem se separa do olhar.

Já temos agora condições de compreender a seguinte passagem: "a angústia surge quando um mecanismo faz aparecer alguma coisa no lugar que chamarei, para me fazer entender, de natural, ou seja, o lugar $(-\varphi)$, que corresponde, do lado direito, ao lugar ocupado, do lado esquerdo, pelo a do objeto do desejo" (Lacan, 1962-63/2005, p. 51). O lugar (- $\varphi$ ) é o da imagem idealizada que o sujeito vê no espelho, e que é percebida como algo que Ihe escapa irremediavelmente, na medida em que ele jamais coincide com ela plenamente. Na angústia diante do espelho, o olhar deixa de ser o objeto elidido e se apresenta no lugar da falta, perturbando a identificação à imagem narcísica.

Quem é o duplo inquietante que olha? Tratase ainda do sujeito, mas do sujeito reduzido a uma parte do corpo, a uma coisa que olha. É como se um pedaço do corpo materializasse artificialmente uma intencionalidade bruta ou pura, um vetor sem cabeça, um Isso que quer algo. Tudo se passa como se tivéssemos acesso por um momento fulgurante ao modo como o Outro nos vê, para além do lugar que ocupamos na rede sócio-simbólica. A estranheza é que me vejo reduzido a um objeto no campo visual do Outro.

O duplo é situação de natureza mais complexa que as anteriores, pois envolve uma 
duplicação: sou ao mesmo tempo a coisa que olha e o Outro que testemunha o olhar. $\mathrm{O}$ que está oculto emerge à plena luz do dia: quando o Outro me interpela, o que vê em mim? É como se eu estivesse abruptamente colocado diante do meu ser como objeto. É como se o duplo revelasse a verdade da interpelação: nós fazemos a experiência do objeto que somos para a interpelação do Outro. A experiência do duplo "nos faz aparecer como objeto, ao nos revelar a não-autonomia do sujeito" (p. 58).

\section{Angústia como defesa contra a pulsão de morte}

A possibilidade de um laço entre o sujeito e o Outro só existe caso seja salvaguardada uma diferença mínima entre eles. Ora, se o trabalho da pulsão de morte consiste precisamente em desfazer os laços, o fim buscado por ela seria, no limite, o apagamento da diferenciação entre o sujeito e o Outro. Tânatos representa uma tendência, presente em todos nós, que visa abolir as distinções e alcançar uma mônada fusional ilimitada com o Outro. Caso tal esforço dominasse de forma irrestrita, a ordem simbólica entraria em colapso; uma vez que é próprio do simbólico estabelecer uma rede de oposições que organiza o mundo em diferenças.

Precisamente nesse ponto, a angústia em jogo no estranhamento exercerá um papelchave, pois ela é uma defesa contra a pulsão de morte. A angústia constitui um protesto contra a abolição das distinções entre sujeito e Outro. Lacan (1962-63/2005) a conceituará como falta da falta: "a angústia não é sinal de uma falta, mas de algo que devemos conceber num nível duplicado, por ser a falta de apoio dada pela falta" (p. 64). Quando nada falta, quando a distância mínima entre os termos corre o risco de ser abolida, temos a emergência da angústia. É o que se pode ler em Freud (1926[1925]/2006) nomeado como angústia automática: reação de defesa, não contra um desejo, mas contra uma excitação excessiva, contra uma exigência de satisfação que excede o princípio de prazer.
A angústia é um recuo horrorizado diante do gozo, ela já envolve um protesto em ser ver completamente absorvido ou completamente excluído do campo do Outro, que são as duas formas opostas da desaparição do sujeito. Creio que esta é a razão pela qual figuras topológicas como a Banda de Moebius são tão caras a Lacan (1962-63/2005) no Seminário 10: estas são ali invocadas para representar a ausência de uma distância entre o sujeito e o Outro, onde não é possível delimitar uma fronteira clara entre o dentro e o fora; como no desenho de Escher em que a formiga passa do exterior para o interior sem corte, sem descontinuidade entre Um e Outro. A angústia ocorre no preciso momento em que a ausência de borda, de limite entre o sujeito e o Outro, se transforma em um problema. A angústia já supõe então um gesto inaugural de recuo diante do gozo.

A tese do Seminário 10 é a de que a angústia é uma mediana entre gozo e desejo: ela supõe um recuo diante do impulso a se fazer de objeto para o Outro. Esse passo atrás é a condição preliminar para que o desejo (ou seja, a falta) se constitua. Inversamente, a angústia seria o sinal da falta que o desejo faz (ou seja, a falta da falta). Lacan conclui que a angústia é anterior logicamente ao desejo (1962-3/2005, p. 179).

Situar a angústia como mediana entre gozo e desejo é reconhecer seu papel como protagonista da estruturação psíquica. A angústia é um afeto fundamental, que torna possível ao sujeito defender-se do gozo incestuoso e fazer um apelo ao Pai. Em seu sentido mais fundamental, a angústia é uma defesa contra a pulsão de morte. Contudo, recordemos que esse artigo não pretende elaborar uma teoria unificada da angústia. Por conta da limitada extensão do artigo, deixou-se de fora da análise outra modalidade da angústia, que é uma forma logicamente posterior à primeira. Maiores indicações sobre isso serão dadas nas considerações finais.

\section{Considerações finais}

O grupo de fenômenos apresentados em $O$ estranho (Freud, 1919/2006) é extremamente heteróclito, resultante de uma mistura de 
registros distintos, indo desde uma perturbação momentânea do imaginário especular até distúrbios mais permanentes, como os ligados à ameaça de castração e a compulsão à repetição. Nesse sentido, o esforço de Lacan deve ser saudado, ao evidenciar a falta da falta como princípio que rege tais manifestações de angústia - o que não é perceptível de forma óbvia.

Importa notar que o valor operatório de um conceito é demonstrado quando este permite reconhecer a identidade subjacente às manifestações as mais heterogêneas entre si. $\mathrm{A}$ circunscrição da identidade não se faz meramente por um esforço de abstração no sentido aristotélico, ou seja, como extração do que há de comum a uma pluralidade. Isso porque $o$ comum ou o idêntico frequentemente não se mostram na percepção; o que significa que o trabalho do conceito é justamente produzir evidências, estabelecer relações que não são aparentes, aproximar temas que aparentemente nada tem de semelhantes.

Gostaria agora de apontar algumas questões que foram disparadas por esta pesquisa e serão investigadas em futuros trabalhos. $\mathrm{O}$ interesse é o de estabelecer os limites de validade do artigo, bem como o de afirmar a sua fecundidade na sugestão de novos tópicos de pesquisa.

Por uma questão metodológica, a artigo concentrou-se na relação entre angústia e gozo. Seria necessário igualmente investigar mais detidamente a relação entre angústia e desejo. Sobre esse assunto, limitamo-nos aqui a apontar o papel da angústia como condição prévia à constituição do desejo. Tal formulação equivale em grande parte à noção freudiana de angústia automática. Num próximo trabalho, pretende-se desenvolver a diferença entre a angústia automática e a angústia-sinal, já que esta última aparece geralmente no texto freudiano como um tipo de afeto que sinaliza justamente a emergência de um desejo já constituído. A hipótese seria que, enquanto a angústia automática é constitutiva do desejo, o sinal de angústia supõe um desejo já constituído. A angústia automática seria anterior logicamente ao sinal de angústia.

Outro ponto que foi aqui apenas esboçado é o seguinte: e se o primeiro Outro for precisamente representado por alguém que não interpela a criança? Não a olha, não a toca, não fala com ela, exibindo graves carências no que diz respeito a uma certa maternagem prévia? Este é um tópico muito sugestivo de novas pesquisas. Limito-me aqui a apontar o seguinte: um Outro invasivo que se apodere da criança equivale, num certo sentido, a um Outro que a deixa à própria sorte. Isso porque tanto a inclusão, quanto a exclusão total de Um pelo Outro, têm ambas o mesmo resultado: o apagamento da diferença mínima entre os termos, a destruição da possibilidade de laço, o colapso da ordem simbólica.

Por último, a definição freudiana clássica da angústia como resultante da perda do objeto pode ser examinada de forma renovada. Tudo depende do sentido que se dá ao termo objeto. Caso seja entendido como causa do desejo, devemos lembrar que o objeto-causa não é aquele que sacia inteiramente a falta, mas sim o a que provoca. Ora, se a falta é que sustenta o desejo, a perda do objeto-causa equivaleria à perda do desejo. A angústia sinalizaria então a falta da falta. 


\section{Rosane Zétola Lustoza}

Doutora em Teoria Psicanalítica pela Universidade Federal do Rio de Janeiro, Rio de Janeiro - Brasil. Docente da Universidade Federal do Paraná, Curitiba - PR. Brasil.

E-mail: rosanelustoza@yahoo.com.br

\section{Endereço para envio de correspondência:}

Universidade Federal do Paraná, Departamento de Psicologia, Praça Santos Andrade, 50. Centro. CEP: 86000-000. Curitiba - PR. Brasil.

Recebido 12/08/2014, Aprovado: 10/03/2015. 
Referências
Brousse, M. H. (2007). Strange objects, immaterial objects: why does Lacan include the voice and the gaze in the series of freudian objects? International Lacanian Review. Recuperado em 28 de agosto de 2014 de http://www.lacancircle.net/ MHBStrange\%20objects.pdf

Didier-Weil, A. (2002). Pai no real - Pai simbólico - Pai real. In J. Moingt, M. M. Chatel, G. Gaufey, J. J. Moscovitz, M. Pradelles, I. Diamantis, et al, Littoral: Do pai. (P. Abreu, trad., pp. 357-368). Rio de Janeiro, RJ: Campo Matêmico.

Freud, S. (2006). O estranho. In Edição standard brasileira das obras psicológicas completas de Sigmund Freud. (J. Salomão, trad., vol. 17. pp. 237-270). Rio de Janeiro, RJ: Imago. (Trabalho original publicado em 1919).

Freud, S. (2006). Inibições, sintomas e ansiedade. In Edição standard brasileira das obras psicológicas completas de Sigmund Freud. (J. Salomão, trad., vol. 20, pp. 91-167). Rio de Janeiro, RJ: Imago. (Trabalho original publicado em 1926[1925]).
Freud, S. (2006). Além do princípio do prazer. In Edição standard brasileira das obras psicológicas completas de Sigmund Freud. (J. Salomão, trad., vol. 18, pp. 17-75). Rio de Janeiro, RJ: Imago. (Trabalho original publicado em 1920).

Hoffman, E. T. A. (2010). O homem da areia. (A. Quintella, trad.). Rio de Janeiro: Rocco.

Lacan, J. (2005). Seminário 10: A angústia. (V. Ribeiro, trad.). Rio de Janeiro, RJ: Jorge Zahar. (Trabalho original publicado em 1962-63).

Lacan, J. (2002). Seminário 3: As psicoses. (A. Menezes, trad.). Rio de Janeiro, RJ: Jorge Zahar. (Trabalho original publicado em 1955-56).

Leader, D. (2013). O que é loucura? Delírio e sanidade na vida cotidiana. (V. Ribeiro, trad.). Rio de Janeiro, RJ: Jorge Zahar.

Miller, J. A. (1997). Lacan elucidado: Palestras no Brasil. Rio de Janeiro, RJ: Jorge Zahar.

Van Haute, P. (2002). Against adaptation: Lacan`s subversion of the subject. New York, NY: Other Press. 